\title{
TRATAMENTO DE SEMENTES DE CEBOLA COM EXTRATO DE PRÓPOLIS E Plectranthus amboinicus NO CONTROLE DE Aspergillus sp.
}

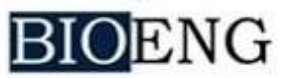

\author{
B. L. Carvalho, E. P. Souza, L. V. S. Anjos, P. G. Nakada-Freitas",
} A. I. I. Cardoso, T. S. Amador, T. P. Santos, T. H. Magalhães

UNESP - Universidade Estadual Paulista, Faculdade de Ciências Agrárias e Tecnológicas (FCAT), Dracena, SP, Brasil

Article history: Received 30 October 2018; Received in revised form 12 December 2018; Accepted 19 December 2018; Available online 30 March 2019.

\section{RESUMO}

Com a grande preocupação pela saúde e a preservação do meio ambiente, a busca por fontes alternativas de controle de doenças vem crescendo na agricultura. Isso porque os agrotóxicos estão sendo usados de forma indiscriminada, colocando em risco a saúde humana e o meio ambiente. As recentes pesquisas mostram a variedade de extratos vegetais que possuem substâncias bioativas eficientes no controle de patógenos. Por este motivo, o presente trabalho teve por objetivo avaliar o efeito de extrato de própolis e Plecthanthus amboinicus no tratamento de sementes de cebola inoculadas com Aspergillus sp. As sementes de cebola foram inoculadas com o fungo Aspergillus flavus. Posteriormente foram aplicados os tratamentos com agitação de cinco minutos em soluções de própolis e P. amboinicus nas concentrações: $0 ; 5 ; 15 ; 25 \%$. O experimento foi montado em esquema fatorial $2 \times 4$ em delineamento inteiramente casualizado com cinco repetições. Para as soluções de $P$. amboinicus houve o preparo de meios de cultura com BDA (batata-dextrose-ágar) e inseridos discos de $5 \mathrm{~mm}$ do fungo, para que houvesse a verificação do efeito in vitro no desenvolvimento do patógeno. As características avaliadas foram: diâmetro do halo de crescimento do fungo (teste in vitro); teste de sanidade; primeira contagem de germinação; germinação ; massa seca de plântula; comprimento de raiz e parte aérea de plântula e teste de emergência. Os extratos de hortelã-pimenta e de própolis não foram eficientes no controle do fungo Aspergillus sp., mediante as concentrações de estudo. $\mathrm{O}$ extrato de hortelã-pimenta utilizado no tratamento de sementes de cebola pode ter provocado fitotoxidez, desencadeado menores valores para a maioria das características de qualidade fisiológica destas sementes, comparativamente ao extrato de própolis.

Palavras-chave: Allium cepa, extrato vegetal, controle fitossanitário.

\section{TREATMENT OF ONION SEEDS WITH PROPOLIS EXTRACT AND Plectranthus amboinicus IN THE CONTROL OF Aspergillus sp.}

\begin{abstract}
With a great concern for health and a preservation of the environment, the search for alternative sources of disease control and growth in agriculture. This is because agrochemicals are being used indiscriminately, putting human health and the environment at risk. As recent research shows which have efficient bioactive substances in the control of pathogens. For this reason, the objective of this work was to evaluate the effect of propolis extract and

*pamela.nakada@unesp.br
\end{abstract}


Plecthanthus amboinicus without treatment of onion seeds inoculated with Aspergillusflavus. As onion seeds were inoculated with the fungus Aspergillus sp. Subsequently, the treatments were applied with agitation of five minutes in solutions of propolis and P. amboinicus in the concentrations: $0 ; 5 ; 15 ; 25 \%$. The experiment was set up in a $2 \times 4$ factorial scheme in a completely randomized design with five replicates. And for the solutions of P. amboinicus, culture media were prepared with BDA (potato-dextrose-agar) and $5 \mathrm{~mm}$ discs were inserted into the fungus, so that there was no evidence of in vitro development of the pathogen. As evaluated characteristics were: halo diameter of fungus growth (in vitro test); sanity test; first germination count; germination; dry mass of seedlings; root overhead length; length and emergency test. Peppermint and propolis extracts were not efficient in the control of the Aspergillus sp. fungus, by means of study concentrations. $P$. amboinicus extract used to treat onion seeds may have caused phytotoxicity, triggering lower values for most of the physiological quality characteristics of these seeds compared to the propolis extract.

Keywords: Allium cepa, vegetable extract, phytosanitary control.

\section{INTRODUÇÃO}

Com o uso indiscriminado dos defensivos agrícolas, a sociedade tem cobrado cobrado do poder público ações que minimizem o uso destes produtos para que o uso desses produtos seja cada vez mais restrito (BRASIL, 2003). E por conta disso, muitos estudos têm procurado formas alternativas para diminuir seu uso para manter em segurança tanto a saúde humana como o meio ambiente. E como forma alternativa para o controle, têm-se estudado os efeitos dos extratos vegetais (DIAS et al., 2000; AMARAL et al., 2002) e óleos essenciais (PANDEY et al., 2000; OKA et al., 2000; OKA, 2001; PEREZ et al., 2003; LOPES et al.,2005), pois são produtos que em muitos estudos já mostraram eficiência no controle de patógenos.

Os extratos vegetais são úteis no manejo de diversas doenças, principalmente na agricultura orgânica, pois representam uma alternativa na proteção das lavouras (BRASIL, 2003; SALGADO et al., 2003). Isso ocorre por possuírem princípios ativos que produzem compostos tóxicos aos patógenos (SALGADO; CAMPOS, 2003).

Com o abundante uso de defensivos agrícolas, em alguns casos houve seleção de patógenos resistentes a estes. Por conta disso, os extratos vegetais vem sendo utilizados como alternativas nos tratamentos contra diferentes patógenos, isso porque seus compostos têm demonstrado eficiência no controle de diversos microrganismos. Esse fato possivelmente é por conta da interação de inúmeras moléculas que existem nos extratos (CARVALHO et al., 2014).

Os extratos vegetais e óleos essenciais são focos de diversos estudos para que haja redução no uso de fungicidas sintéticos e que possuem resultados positivos no controle de patógenos. As pesquisas realizadas com extratos e óleos essenciais tem demonstrado potencial das plantas medicinais em controle de patógenos, pois possuem ação antifúngica que inibe o crescimento e germinação de esporos (BORGES et al., 2013).

Estudo realizado por Portilho et al. (2013), demonstraram que extratos de própolis possuem potencial antibacteriano, anti-inflamatório e antifúngico, além das propriedades farmacoterapêuticas, e o própolis é amplamente utilizado como alternativa para substituição aos antibióticos.

Fungos que atacam sementes, assim como o Aspergillus sp. causam sérios prejuízos como deterioração, lesões, morte de plantas e sementes, entre outros danos. A preocupação do ataque desses fungos se deve não apenas às manifestações no início do cultivo, mas também em plantas já adultas, por isso o tratamento eficiente de 
sementes é de tamanha importância na agricultura (CARVALHO et al., 2012).

Nesse contexto, por conta dos diversos estudos com resultados positivos utilizando extratos vegetais de plantas medicinais, o presente estudo possui relevância para o tratamento alternativo de sementes, sem agredir o meio ambiente.

\section{MATERIAL E MÉTODOS}

O experimento foi desenvolvido no Laboratório de Fisiologia Vegetal da Universidade Estadual Paulista/ Faculdade de Ciências Agrárias e Tecnológicas do Campus de Dracena-SP, no período de agosto a novembro de 2017.

A espécie estudada foi a cebola (Allium cepa), sendo suas sementes isentas de qualquer tratamento. Posteriormente, as sementes foram inoculadas com Aspergillus flavus em meio BDA (batata-dextrose-ágar) juntamente com restritor hídrico manitol na concentração de $33 \mathrm{~g} \mathrm{~L}^{-1}$ para obtenção de 0,8 MPa de potencial hídrico (MACHADO et al. 2001). Esse procedimento é utilizado para evitar a germinação de sementes durante a inoculação das mesmas. Após o desenvolvimento completo do fungo neste meio, as sementes permaneceram em camada única, por período de 9 horas (ANJOS et al., 2017) para que pudessem ser infectadas, seguindo de secagem natural sob temperatura a $25^{\circ} \mathrm{C}$ por 48 horas.

Os tratamentos consistiram de dois extratos (própolis e $P$. amboinicus) em quatro concentrações $(0 ; 5 ; 15$ e $25 \%)$ e as sementes foram tratadas sob agitação por 5 minutos. Assim o experimento foi desenvolvido em esquema fatorial 2 x 4 (2 extratos e 4 concentrações), em delineamento inteiramente casualizado com cinco repetições. Após o tratamento, foi retirado o excesso das soluções das sementes com auxílio de peneira, e colocadas sobre papel toalha. Após secagem, aplicaram-se os testes para avaliação da qualidade fisiológica e sanitária.

As características avaliadas foram: germinação (\%), contabilizado plântulas
Portanto, o objetivo deste trabalho foi verificar o feito no controle e na qualidade fisiológica de sementes de cebola inoculadas com Aspergillus sp. e tratadas com Plectranthus amboinicus e extrato de própolis, e verificar o efeito de $P$. amboinicus no controle de Aspergillus sp. in vitro.

normais após 12 dias da semeadura (BRASIL, 2009a); primeira contagem de germinação (\%) contabilizadas as plântulas normais após seis dias da semeadura do teste de germinação; massa seca de plântula: coletou-se todas plântulas normais do teste de germinação que foram colocadas em sacos de papel dentro da estufa $\left(40^{\circ} \mathrm{C}\right)$ com circulação de ar por período de 48 horas quando se estabilizou a massa $(\mathrm{mg})$; comprimento de parte aérea e raiz de plântulas, foram amostradas ao acaso de 10 plântulas normais do teste de germinação, expresso em centímetros; emergência (\%): foram semeadas sementes em bandejas para mudas de 162 células em substrato para mudas, e a avaliação ocorreu aos 12 dias após a semeadura, expresso em porcentagem; teste de sanidade (Blotter Test, em que se utilizou o método do papel filtro em placas de Petri permanecendo em câmara a $20^{\circ} \mathrm{C}$ por sete dias sob regime alternado de luz e escuro por 12 horas, e após esse período foram contabilizados a presença do $A$. flavus em microscópio estereoscópico, expresso em porcentagem (BRASIL, 2009b).

Foram preparadas soluções de $P$. amboinicus com meios de cultura BDA nas concentrações $(0 ; 5 ; 15$ e $25 \%)$. Depois de solidificado o meio, foi inserido disco de 5 mm de Aspergillus sp. no centro da placa de Petri para verificar o efeito in vitro do desenvolvimento do patógeno, que foi avaliado pelo diâmetro do halo e expresso em centímetros.

Os dados foram submetidos a análise de variância, os extratos foram comparados pelo teste $\mathrm{t}$ e para as 
concentrações, ajustou-se análise de regressão a 5\% de probabilidade.

\section{RESULTADOS E DISCUSSÃO}

A análise estatística revelou diferença significativa para efeito do extrato de própolis e hortelã-pimenta para as características de germinação, comprimento

de raiz, comprimento de parte aérea, emergência e porcentagem de Aspergillus sp. do teste de sanidade (Tabela 1).

Tabela 1. Germinação, comprimento de radícula (CR), comprimento de parte aérea (CPA), teste de emergência e porcentagem de Aspergillus sp. em sementes de cebola inoculadas com Aspergillus sp. e tratadas com extrato de hortelã-pimenta e própolis. Dracena-SP, 2017.

\begin{tabular}{|c|c|c|c|c|c|}
\hline Extrato & $\begin{array}{c}\text { Germinação } \\
(\%)\end{array}$ & $\begin{array}{l}\mathrm{CR} \\
(\mathrm{cm})\end{array}$ & $\begin{array}{l}\text { CPA } \\
(\mathrm{cm})\end{array}$ & Emergência (\%) & $\begin{array}{c}\text { Aspergillus sp. } \\
(\%)\end{array}$ \\
\hline hortelã-pimenta & $60 \mathrm{~b}^{*}$ & $0,35 \mathrm{~b}$ & $1,17 \mathrm{~b}$ & $50 \mathrm{a}$ & $98 \mathrm{a}$ \\
\hline própolis & $80 \mathrm{a}$ & $1,42 \mathrm{a}$ & $3,58 \mathrm{a}$ & $45 \mathrm{~b}$ & $96 \mathrm{~b}$ \\
\hline $\mathrm{CV}(\%)^{* *}$ & 17,2 & 28,2 & 26,9 & 12,9 & 3,3 \\
\hline
\end{tabular}

*Médias seguidas por mesma letra na coluna não diferem entre si pelo teste $\mathrm{t}$ a $5 \%$ de probabilidade.

${ }^{* *} \mathrm{CV}(\%)$ : coeficiente de variação.

Observa-se na Tabela 1 que o extrato de própolis se destacou para as características de germinação, comprimento de raiz e parte aérea, quando comparado ao extrato de hortelã-pimenta, em que houve germinação de $80 \%$, e tanto para CR e CPA, resultaram em valores maiores que o dobro do extrato de hortelã-pimenta, 1,42 e $3,58 \mathrm{~cm}$, respectivamente, mostrando assim que independente da concentração, o extrato de própolis resultou em melhores resultados quanto as características de vigor.

Quanto a emergência de plântulas e a porcentagem de Aspergillus sp. em sementes de cebola inoculadas e tratadas com os extratos (Tabela 1), ocorreu o inverso, ou seja, houve destaque para a hortelã-pimenta em relação ao extrato de própolis. Observou-se 50 e $45 \%$ no teste de emergência, e 98 contra $96 \%$ de Aspergillus sp. para o extrato de hortelã-pimenta e própolis, respectivamente. Vale destacar que a diferença foi apenas cinco pontos percentuais, sendo assim pouco relevante para o teste de emergência.

Do mesmo modo ocorreu no teste de sanidade, os resultados mostraram que nem um dos dois extratos conseguiram controlar o fungo Aspergillus sp. pois obtiveram resultados próximos a $100 \%$ de contaminação, e baixa diferença entre si (dois pontos percentuais, 98 contra 96\%). Segundo Oliveira et al. (2007), a hortelãpimenta apresenta propriedades em sua composição que possuem atividades antimicrobianas, e que essas propriedades estão diretamente ligadas aos compostos timol e carvacol, embora não se mostrou eficiente no presente estudo.

Em trabalho realizado por Pinheiro et al. (2015), mostrou que a hortelã-pimenta em concentração de $0,12 \%$ teve maior eficiência do que a utilização de alguns herbicidas. Nesse estudo, os autores compararam a utilização de herbicidas sintéticos e alternativos para mostrar que em alguns casos, o tratamento alternativo também é efetivo.

Mas apesar dessas características, a eficiência do extrato de hortelã-pimenta depende principalmente das concentrações dos compostos que apresentam (AGUIAR, 2004).

$\mathrm{Na}$ figura 2, pode-se observar que não houve diferença na contaminação nas concentrações do teste com o extrato de própolis, mesmo na maior concentração a semente foi contaminada pelo fungo. Destaca-se que este produto possui 
eficiência antimicrobiana, porém sua eficácia depende do local de produção (FERNANDES et al., 2006).

Em estudo realizado por Souza et al. (2017), demonstraram a eficiência linear de atuação do extrato de própolis no controle do fungo Penicillium sp. À medida que se aumentavam as concentrações, limitando-se a $20 \%$, houve total inibição do crescimento micelial do fungo, no teste realizado in vitro. Apesar do presente trabalho não ter apresentado o mesmo resultado de Souza et al. (2017) quanto ao teste de sanidade, porém com relação aos testes de germinação e vigor (Tabela 1), observou-se que o extrato de própolis não afetou a qualidade fisiológica das sementes de cebola.

Nesse estudo, realizou-se o teste in vitro inoculando-se o Aspergillus sp. em meio BDA juntamente com as concentrações de hortelã-pimenta em estudo, e não houve diferença significativa, observado $72 \mathrm{~mm}$ de média geral do diâmetro do halo de desenvolvimento do fungo, significando que este extrato não proporcionou efeito antimicrobiano, contradizendo a afirmação de Oliveira et al. (2007).
A respeito dos resultados inferiores observados em sementes tratadas com extrato de hortelã-pimenta, é possível explicar tal fenômeno pela ocorrência de efeito fitotóxico (Tabela 1).

Quanto aos resultados de matéria seca por plântula (Tabela 2), ocorreu efeito significativo para interação dos extratos com as concentrações. $\mathrm{Na}$ concentração $0 \%$, apesar de haver diferença entre valores, não houve diferença estatística, o que já se esperava, pois nos dois tratamentos, utilizou-se apenas água para tratar as sementes. Já nas concentrações de 5, 15 e $25 \%$ houve diferença significativa entre os extratos, em que se observa em 5 e $15 \%$ do extrato de hortelã-pimenta, superioridade dos resultados quando comparado ao de própolis, com valores de 72 e $50 \mathrm{mg}$, respectivamente. E na maior concentração (25\%), ocorreu o oposto, observado maior valor para o extrato de própolis $(68 \mathrm{mg})$ em relação a hortelã-pimenta $(40 \mathrm{mg})$. Esse resultado reforça a discussão da tabela 1 , pois demonstra que na maior concentração prejudicou as características fisiológicas da semente de cebola, que são as características de germinação, comprimento de radícula e parte aérea.

Tabela 2. Matéria seca de plântulas de cebola inoculadas com Aspergillus sp. e tratadas com concentrações de extrato de hortelã-pimenta e própolis. Dracena-SP, 2017.

\begin{tabular}{ccc}
\hline \multirow{2}{*}{ Extrato $(\%)$} & \multicolumn{2}{c}{ matéria seca $(\mathrm{mg})$} \\
\cline { 2 - 3 } & hortelã-pimenta & própolis \\
\hline 0 & $39 \mathrm{a}$ & $54 \mathrm{a}$ \\
5 & $72 \mathrm{a}$ & $46 \mathrm{~b}$ \\
15 & $50 \mathrm{a}$ & $24 \mathrm{~b}$ \\
25 & $40 \mathrm{~b}$ & $68 \mathrm{a}$ \\
\hline
\end{tabular}

CV $(\%)^{* *} \quad 29,7$

*Médias seguidas por mesma letra na linha não diferem entre si pelo teste $\mathrm{t}$ a $5 \%$ de probabilidade.

**CV $(\%)$ : coeficiente de variação.

Houve diferença significativa para primeira contagem de germinação e para porcentagem de Aspergillus sp. referente a fonte de variação concentração de extrato (Figura 3), ajustando-se regressão linear para ambas as características. Nota-se para primeira contagem de germinação, diferença apenas de cinco pontos percentuais, partindo de 20 para $15 \%$ (referentes à concentração 0 e 25\%), ou seja, aumentando-se a concentração do extrato, afetou o vigor das sementes de cebola, provavelmente o princípio ativo pode ter afetado o eixo embrionário ou $\mathrm{o}$ material de reserva. 
Já no teste de sanidade, partiu-se da menor para a maior concentração, de 99 para $92 \%$ de contaminação com Aspergillus sp (Figura 1). Embora tenha ocorrido

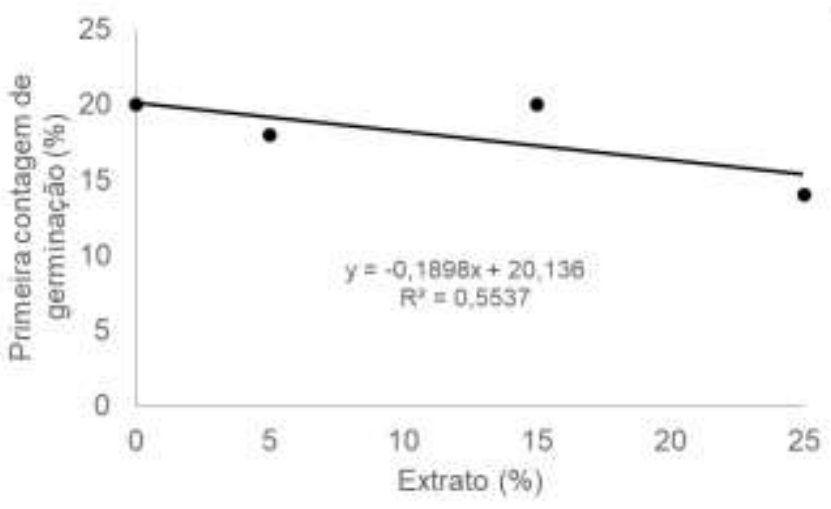

diferença significativa, observa-se que os extratos não proporcionaram controle eficiente contra o Aspergillus flavus.

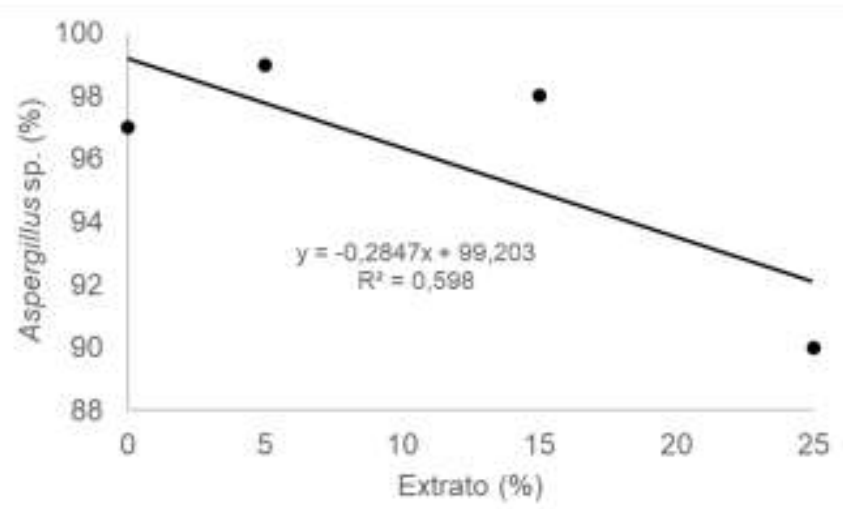

Figura 1. Primeira contagem de germinação e porcentagem de Aspergillus sp. em sementes tratadas de cebola inoculadas com Aspergillus sp. Dracena-SP, 2017.

\section{CONCLUSÕES}

Os extratos de hortelã-pimenta e de própolis não foram eficientes no controle do fungo Aspergillus flavus, mediante as concentrações de estudo.

O extrato de hortelã-pimenta utilizado no tratamento de sementes de

\section{REFERÊNCIAS BIBLIOGRÁFICAS}

AMARAL, D.R.; OLIVEIRA, D. F.; CAMPOS V. P.; CARVALHO, D. A. Efeito de extratos vegetais na eclosão, mobilidade, mortalidade e patogenicidade de Meloidogyne exigua do café. Nematologia Brasileira, v. 26, n. 1, p. 43-48, 2002. ANJOS, L. V. S.; SANTOS, T. P.; SOUZA, E.P.; NAKADA-FREITAS, P. G.; CARDOSO, A.I.I. Tratamento de sementes de cebola com óleo essencial de Melaleuca alternifolia. In: XXIX Congresso de Iniciação Científica da Unesp, 2017, Dracena. Anais do XXIX Congresso de Iniciação Científica da Unesp, 2017.

BORGES, D.I.; ALVES, E.; MORAES, M.B.; OLIVEIRA, D.F. Efeito de extratos e óleos essenciais de plantas na germinação de urediniósporos de Phakopsora pachyrhizi. Revista brasileira de plantas medicinais, v.15, n.3, p. 325-331, 2013. cebola pode ter provocado fitotoxidez, desencadeado menores valores para a maioria das características de qualidade fisiológica destas sementes, comparativamente ao extrato de própolis.

BRASIL. Constituição Federal. Lei $\mathrm{n}^{\circ}$ 10.831, de 23 de dezembro de 2003. (Lei dos Orgânicos) 2003.

BRASIL. Ministério da Agricultura, Pecuária e Abastecimento. Regras para análise de sementes. Brasília: Mapa/ACS, 2009a. 399p.

BRASIL. Ministério da Agricultura, Pecuária e Abastecimento. Manual de Análise Sanitária de Sementes. Brasília: Mapa/ACS, 2009b. 200p.

CARVALHO, A.F.; SILVA, D.M.; SILVA, T.R.C.; SCARCELLI, E.; MANHANI, M.R.Avaliação da atividade antibacteriana de extratos etanólico e de ciclohexano a partir das flores de camomila (Matricaria chamomilla L.). Revista Brasileira de Plantas Medicinais, v. 16, n. 3, p. 521-526, 2014. 
CARVALHO, H.P.; SOUZA, P.E.; ABREU, M.S.; GUIMARÃES, R.M.; CARVALHO, M.L.M.; REIS, R.G.E.Efeito de Colletotrichum gloeosporioides Penz, agente etiológico da mancha manteigosa, na germinação e viabilidade de sementes de cafeeiro.Revista Brasileira de Sementes, v. 34, n. 2, p. 264-271, 2012.

DIAS, C. R.; SCHWAN, A.V.; EZEQUIEL, D. P.; SARMENTO, M. C.; FERRAZ, S.Efeito de extratos aquosos de plantas medicinais na sobrevivência de juvenis de Meloidogyne incognita. Nematologia Brasileira, v. 24, n. 2, p. 203- 210, 2000.

FERNANDES JÚNIOR, A.; LOPES, M.M.R.; COLOMBARI, V.; MONTEIRO, A.C.M.; VIEIRA, E.P. Atividade antimicrobiana de própolis de Apis mellifera obtidas em três regiões do Brasil. Ciência Rural, v.36, n.1, p.294-297, 2006.

LOPES, E.A.; FERRAZ, S.; FREITAS, L.G.; FERREIRA, P.A.; AMORA, D.X. Efeito dos extratos aquosos de Mucuna preta e de Manjericão sobre Meloidogyne incognita e $M$. javanica. Nematologia Brasileira, v. 29, n. 1, p. 67-74, 2005.

MACHADO, J.C.;OLIVEIRA, J.A.; VIEIRA, M.G.G.C.; ALVES, M.C. Inoculação artificial de sementes de soja por fungos, utilizando solução de manitol. Revista Brasileira de Sementes, v. 23, p. 95-101, 2001.

OKA, Y.; NACAR, S.; PUTIEVSKY, E.; RAVID, U.; ZOHARA, Y.; SPIEGEL, Y.Nematicidal activity of essential oils and their components against the root-knot nematode. Nematology. v. 90, n. 7. p. 710715, 2000.

OKA, Y. Nematicidal activity of essential oil components against the root-knot nematode Meloidogyne javanica. Nematology, v. 3, n. 2, p. 159-164, 2001.

OLIVEIRA, R.A.G.; LIMA, E.O.; DE SOUZA, E.L.; VIEIRA, W.L.; FREIRE, K.R.L.; TRAJANO, V.N.; LIMA, I.O.; SILVA-FILHO, R.N. Interference of
Plectranthus amboinicus (Lour.) Spreng essential oil on the anti-Candida activity of some clinically used antifungals. Revista Brasileira de farmacognosia, v. 17, n. 2, p. 186-190, 2007.

PANDEY, R.; KALRA, A.; TANDON, S.; MEHROTRA, N.; SINGH, H. N.; KUMAR, S. Essential oils as potent sources of nematicidal compounds. Journal of Phitopathology. v. 148, p.501-502. 2000.

PÉREZ， M.P.; NAVAS-CORTÉS， J.A.; PASCUAL-VILLALOBOS, M.J.; CASTILHO, P. Nematicidal activity of essential oils and organic amendments from Asteraceae against root-knot nematodes. Plant Pathology, n. 52. p. 395-401. 2003.

PINHEIRO, P. F.; COSTA, A.V.; ALVES T.D.E.A.; GALTER, I.N.;PINHEIRO, C.A.; PEREIRA, A.F.; OLIVEIRA, C.M.; FONTES, M.M. Phytotoxicity and cytotoxicity of essential oil from leaves of Plectranthus amboinicus, carvacrol, and thymol in plant bioassays. Journal of agricultural and food chemistry, v. 63, n. 41, p. 8981-8990, 2015.

SALGADO, S.M.L.; CAMPOS,V.P.; CARDOSO, M.G.; SALGADO, A.P.S. Eclosão e mortalidade de juvenis de segundo estádio de Meloidogyne exigua em óleos essenciais. Nematologia Brasileira, v. 27, n. 1, p. 17- 22, 2003.

SALGADO, S.M.L.; CAMPOS, V.P. Eclosão e mortalidade Meloidogyne exigua em extratos e em produtos naturais. Fitopatologia Brasileira. v. 28. n. 2. p. 166-170. 2003.

SOUZA, E.P.; PERINO, F.H.B.; MOSCATO, B.S. ; FREITAS, P.G.N.; BLUMER, S. ; CARDOSO, A.I.I.; BONINI, C.S.B. ; BONINI NETO, A.Extrato de própolis no controle do Penicillium sp. e na qualidade de sementes de couve-flor. Revista Brasileira de Engenharia de Biossistemas, v. 11, p. 135141, 2017. 